\title{
BMJ Open Patterns of age disparities in colon and lung cancer survival: a systematic narrative literature review
}

\author{
Sophie Pilleron (D) , ${ }^{1}$ Helen Gower, ${ }^{2}$ Maryska Janssen-Heijnen, ${ }^{3,4}$ \\ Virginia Claire Signal, ${ }^{1}$ Jason K Gurney (D) , ${ }^{1}$ Eva JA Morris, ${ }^{5}$ Ruth Cunningham (D) , ${ }^{1}$ \\ Diana Sarfati ${ }^{6}$
}

To cite: Pilleron S, Gower H, Janssen-Heijnen $\mathrm{M}$, et al. Patterns of age disparities in colon and lung cancer survival: a systematic narrative literature review. BMJ Open 2021;11:e044239. doi:10.1136/ bmjopen-2020-044239

- Prepublication history and additional material for this paper is available online. To view these files, please visit the journal online (http://dx.doi.org/10. 1136/bmjopen-2020-044239).

Received 01 September 2020 Revised 18 February 2021 Accepted 26 February 2021

Check for updates

(c) Author(s) (or their employer(s)) 2021. Re-use permitted under CC BY-NC. No commercial re-use. See rights and permissions. Published by BMJ.

For numbered affiliations see end of article.

Correspondence to Dr Sophie Pilleron; sophie.pilleron@gmail.com

\section{ABSTRACT}

Objectives To identify patterns of age disparities in cancer survival, using colon and lung cancer as exemplars. Design Systematic review of the literature.

Data sources We searched Embase, MEDLINE, Scopus and Web of Science through 18 December 2020.

Eligibility criteria We retained all original articles published in English including patients with colon or lung cancer. Eligible studies were required to be populationbased, report survival across several age groups (of which at least one was over the age of 65) and at least one other characteristic (eg, sex, treatment).

Data extraction and synthesis Two independent reviewers extracted data and assessed the quality of included studies against selected evaluation domains from the QUIPS tool, and items concerning statistical reporting. We evaluated age disparities using the absolute difference in survival or mortality rates between the middle-aged group and the oldest age group, or by describing survival curves.

Results Out of 3047 references, we retained 59 studies (20 for colon, 34 for lung and 5 for both sites). Regardless of the cancer site, the included studies were highly heterogeneous and often of poor quality. The magnitude of age disparities in survival varied greatly by sex, ethnicity, socioeconomic status, stage at diagnosis, cancer site, and morphology, the number of nodes examined and treatment strategy. Although results were inconsistent for most characteristics, we consistently observed greater age disparities for women with lung cancer compared with men. Also, age disparities increased with more advanced stages for colon cancer and decreased with more advanced stages for lung cancer.

Conclusions Although age is one of the most important prognostic factors in cancer survival, age disparities in colon and lung cancer survival have so far been understudied in population-based research. Further studies are needed to better understand age disparities in colon and lung cancer survival.

PROSPERO registration number CRD42020151402.

\section{INTRODUCTION}

Poorer cancer survival among older patients has been well documented. ${ }^{1-6}$ Although patients with cancer are increasingly surviving their disease thanks to advances in

\section{Strengths and limitations of this study}

- For the first time, we conducted a systematic review of population-based studies relating to differences in cancer survival between middle-aged and older patients, using colon and lung cancer as exemplar cancers.

- We limited our search to peer-reviewed original articles and letters to Editors published in English up until 18 December 2020.

- We excluded clinical studies and trials due to the strict selection of patients and the common underrepresentation of older patients in these studies.

- We could not conduct any quantitative analysis (such as meta-analysis) because of the vast heterogeneity of the studies included, which prevented us from quantifying the relationship between increasing age and cancer survival.

treatment, ${ }^{2-6}$ those who are older have not benefitted from these advances to the same degree as their middle-aged counterparts, widening the age-related cancer survival gap. $^{257}$

From a clinical point of view, cancer management in older patients may be different to that of middle-aged patients due to higher comorbidity levels, polypharmacy, age-related physiological changes and reduced life expectancy. ${ }^{8}$ In addition, older adults with cancer are often excluded from randomised clinical trials, limiting the evidence they provide in relation to the benefits and risks of different treatment strategies at older ages. ${ }^{9} 10$ Cancer management may also be hindered in older patients with cancer by social factors such as reduced social support ${ }^{1112}$ or healthcare system-related factors such as access to care facilities.

A recent systematic review found that advanced age, low income, low socioeconomic status, presence of comorbidities, advanced stage and poor tumour grade were associated with lower survival among older adults with 
cancer, while female gender and being married were associated with increased survival. ${ }^{13}$ However, the authors did not explore inequalities in cancer survival between age groups, and they excluded studies that included middleaged patients. They also did not focus on any particular cancer sites. This is important, as it is likely that many factors influence age disparities in cancer survival, and they may vary depending on cancer site.

Worldwide, colon and lung cancers are the most common cancer types diagnosed among adults aged 65 years and older. ${ }^{14}$ These two cancer sites have different biology, risk factors and survival outcomes, with colon cancer having a higher 5-year relative survival than lung cancer, ranging from $59 \%$ to $71 \%$ for colon cancer and $15 \%$ to $22 \%$ for lung cancer in high-income countries. $^{7}$ These cancers also have a different pattern of age inequalities in survival over time. In colon cancer, disparities in cancer survival between older and younger adults is mainly observed in the first year following diagnosis, while in lung cancer, the excess mortality in older adults is mainly observed after 5 years of follow-up. ${ }^{515}$

To our knowledge, there has been no attempt to summarise the available literature on age disparities in cancer survival. Thus, in this manuscript we conducted a systematic review of studies that have investigated differences in cancer survival between middle-aged and older patients, using the diverse contexts of colon and lung cancer as exemplars. We aimed to identify (1) patterns of age-related disparities based on patient and clinical characteristics and (2) the potential gaps in knowledge to inform future research.

\section{METHODS AND MATERIALS}

We conducted a systematic literature search of Embase, MEDLINE, Scopus and Web of Science. Using a Boolean approach, we searched for articles including the following keywords: cancer, colon, lung, survival and older patients. Online supplemental table 1 shows the search terms that were used. The search strategy was first set up in Embase (online supplemental table 2), and then adapted for the other databases.

We retained all original articles or letters published in English up until 18 December 2020 that included patients diagnosed with colon or lung cancer. Eligible studies were required to report survival across several age groups (of which at least one was over the age of 65) and investigate the impact of increasing age on survival stratified by at least one other characteristic (eg, sex, treatment). We included population-based studies only. We excluded clinical studies and trials due to their strict inclusion criteria and the under-representation of older adults. ${ }^{9}$ The PICO criteria for our review are shown in online supplemental table 3 .

\section{Study selection}

We selected eligible articles using a three-step process: (1) after removal of duplicate records, SP screened all titles to remove irrelevant studies, with a $10 \%$ random sample of these verified by VCS. (2) For each study retained after title screening, SP screened all abstracts, with a $10 \%$ random sample of these checked by HG. (3) The full-texts of all retained papers were retrieved and assessed twice for eligibility by SP, with a $10 \%$ random sample verified by HG. Online supplemental table 4 lists all references not included in the final selection after screening the full text, along with the justification of their exclusion. In addition, SP scanned the reference lists of all included studies for additional relevant studies. If one of the authors referenced a study that met the eligibility criteria, we included it if relevant. The origin of the studies (ie, database search or reference lists) are specified in table 1 for included papers.

\section{Data collection process and data items}

For all included studies, SP and HG independently extracted the following information: first author; year of publication; location of data; study objective; cancer type; stage at diagnosis; age at diagnosis; exclusion criteria; cancer diagnosis period; source of cancer data; source of mortality data; measure of age; source of age; sampling; time origin; end of follow-up; survival/mortality metrics; method; sample size; time of follow-up; number of deaths; characteristic(s) studied and their definition.

In cases where an eligible study contained no numerical survival estimates but presented one or more graphs showing survival by age group stratified by another characteristics (eg, sex, stage at diagnosis), SP emailed the corresponding author to request numerical data. ${ }^{16-21}$

SP and HG independently assessed the quality of included studies against selected evaluation domains from the QUIPS tool: ${ }^{22}$ study participation; prognostic factor measurement; outcome measurement; and statistical reporting. We adapted the items within each domain to our study. Also, we used selected items among those suggested by Altman $e t a l^{23}$ to assess statistical reporting.

Where numerical survival estimates were available, we assessed age disparities in survival by calculating the absolute difference in (overall or relative) survival between middle-aged patients (age groups including the age of 50 when possible, depending on the availability of data) and the oldest age group (age groups including the age of 65 years old or older ages, depending on the availability of data), to give a sense of trends and inform discussion. When survival estimates were available for several periods of cancer diagnosis, we retained estimates for the latest period. Where numerical survival estimates were not available, we described survival curves by age group and the characteristic(s) of interest. For mortality rates, we computed the absolute difference between the mortality rate in the oldest age group with that in the middle-aged age group, again to give a sense of trends and inform discussion. We reported CIs or $\mathrm{p}$ values when available.

We collected and logged references in Zotero V.5.0.73. We used the Rayyan free web application for the title and abstract screening. ${ }^{24}$ The Preferred Reporting Items 


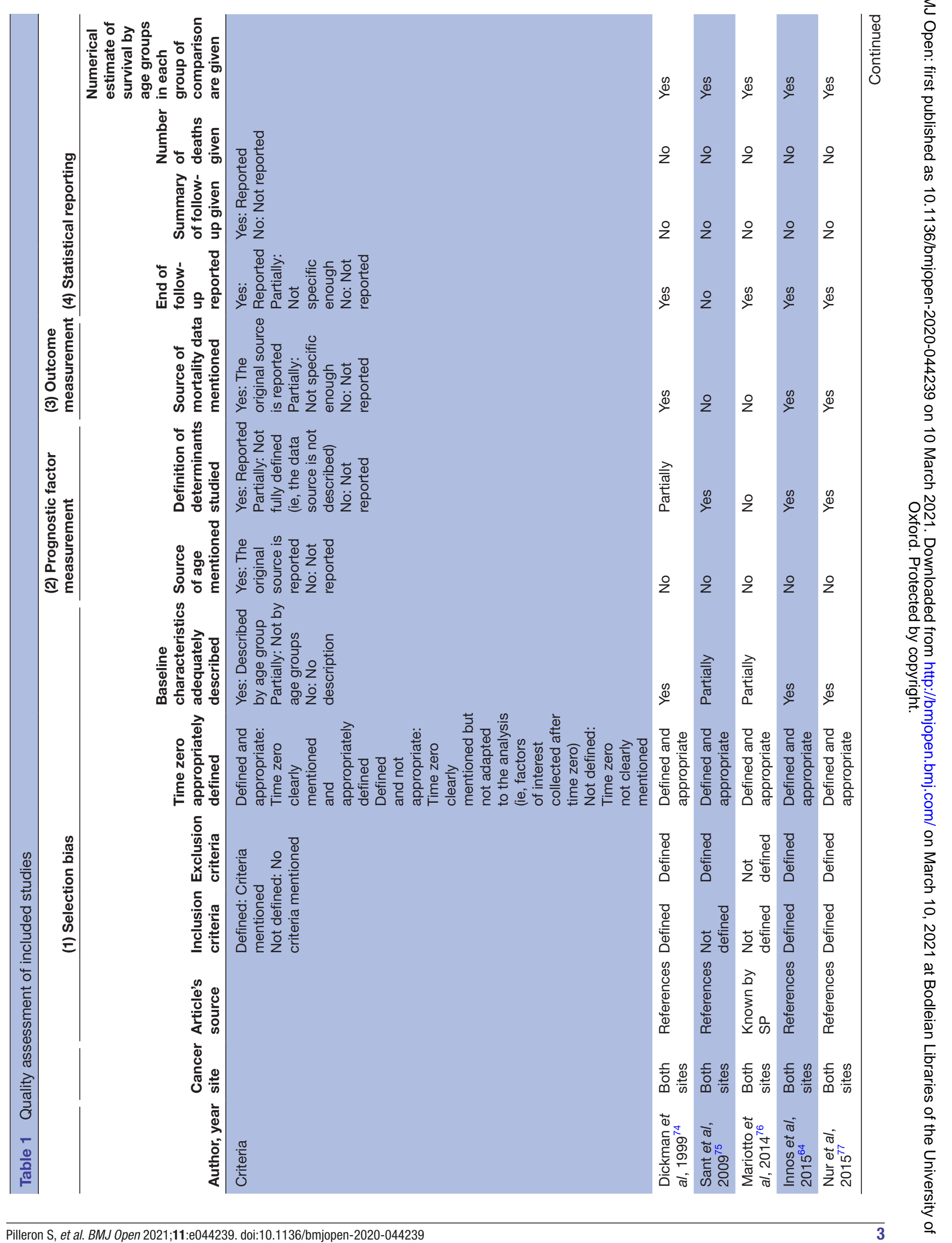




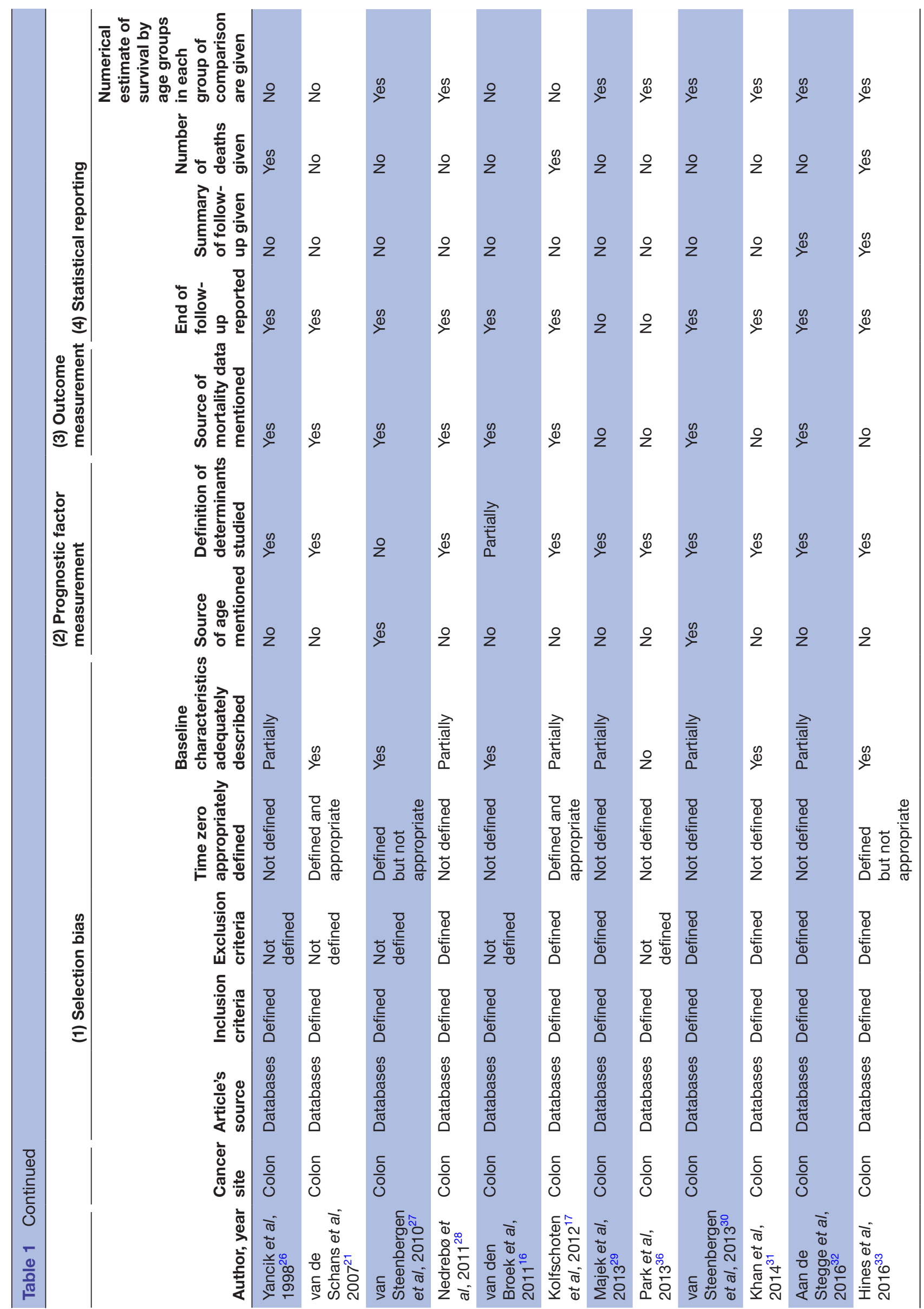




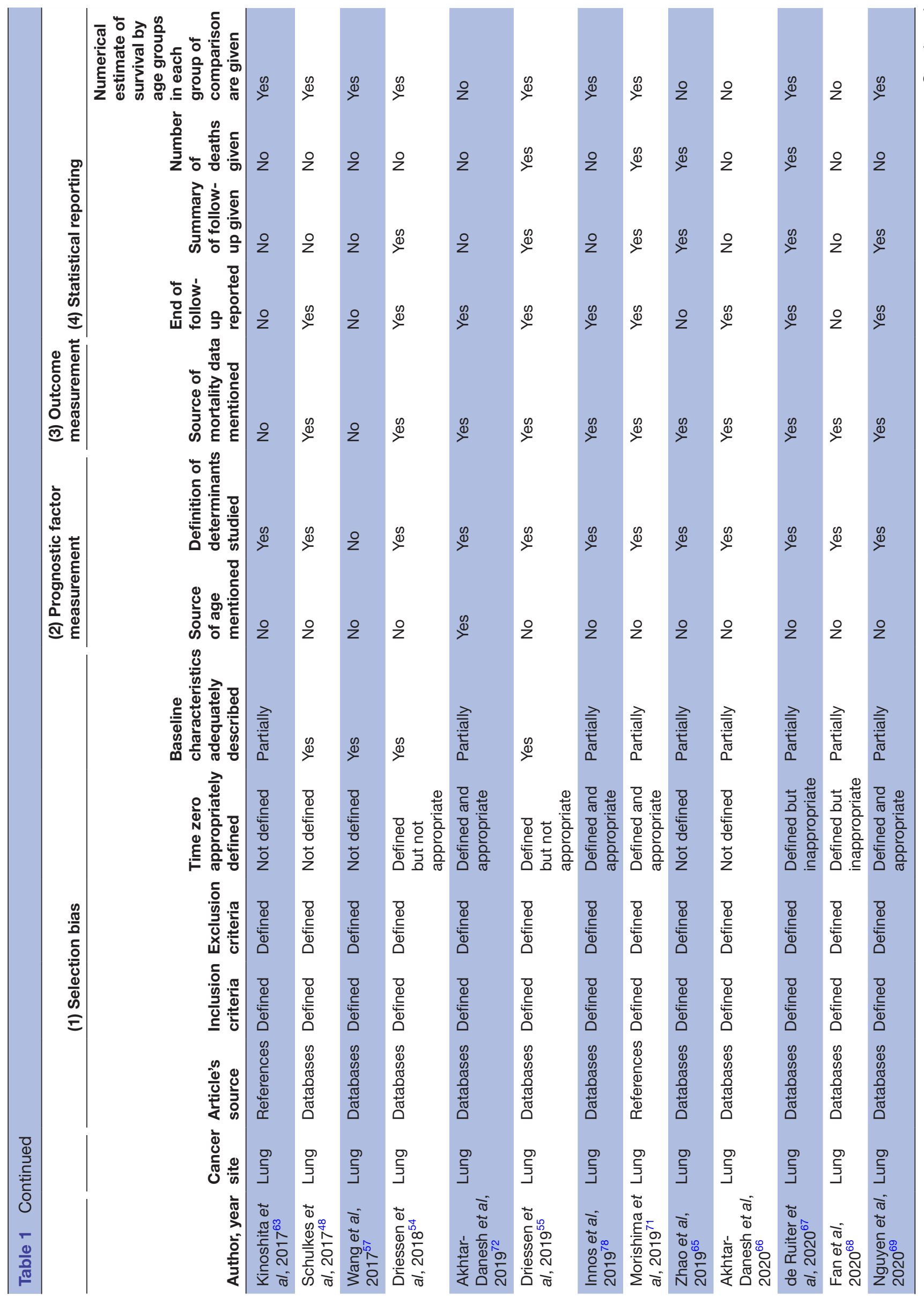




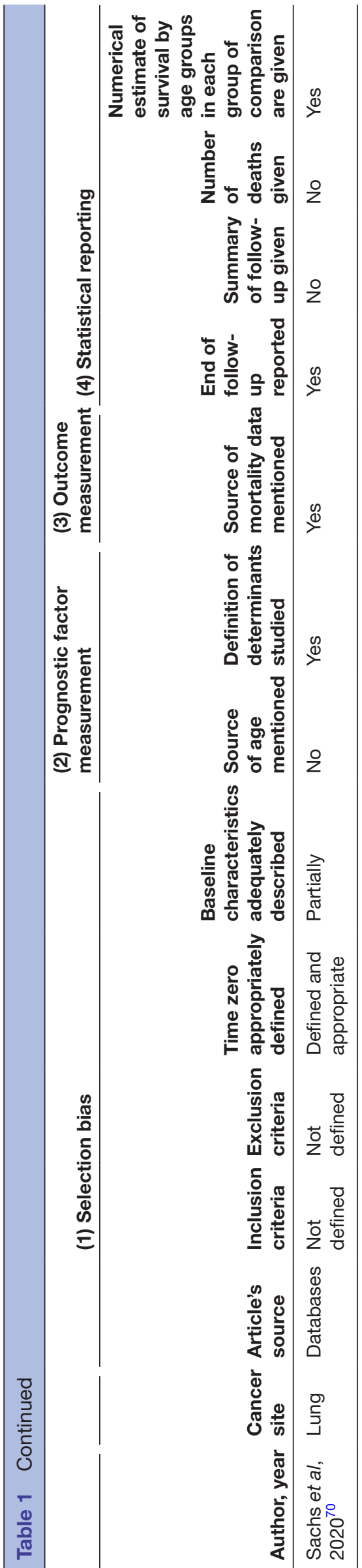

for Systematic Reviews and Meta-Analyses guidelines were used for the review, ${ }^{25}$ and we registered our review protocol in the International Prospective Register of Systematic Review.

Patient and public involvement

No patients were involved.

\section{RESULTS}

We screened 3047 references for eligibility and retained 59 studies (figure 1): 20 studies on colon cancer survival, ${ }^{16} 17202126-4134$ studies on lung cancer survival $^{181942-73}$ and 5 studies which detailed both colon and lung cancer survival. ${ }^{64-77}$

\section{Quality assessment}

Essential information to appropriately interpret survival analysis results (ie, the number of events, end of follow-up, numerical estimates of survival) were missing in a substantial proportion of the included studies. For example, 18 studies did not report the time origin from which the survival time had been calcu-

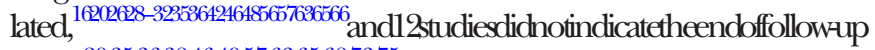
date. ${ }^{293536384649576365687375}$ In 47 articles the authors did not

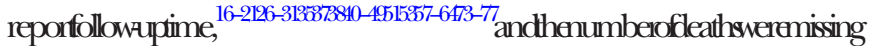
in 43 articles. ${ }^{16} 18-21$ 27-3235 $384042-4648495354575860-646668-7072-78$ Only four studies reported the source of age at diagnosis (frommedicalrecords). ${ }^{27304972}$ In 12studies, theauthors did notprovidenumericalsurvival estimates. ${ }^{16-19212637415165666872}$

\section{Characteristics of included studies}

All studies used population-based cancer registry data. Two studies analysed a random sample of patients. ${ }^{26} 61$

Of the 25 studies examining colon cancer, 6 studies investigated age disparities in colon cancer survival (table 2). ${ }^{16173132344159}$ Seven studies used data from The Netherlands, ${ }^{16172127303240}$ and six presented data from the USA. ${ }^{26} 3133343776$ The remaining studies used data from Estonia, ${ }^{64}$ England, ${ }^{38} 77$ Japan, ${ }^{39}$ Finland, ${ }^{74}$ Germany, ${ }^{29}$ Korea $^{3536}$ and Australia. ${ }^{20}$ One study used data from $>20$ Europeans countries, ${ }^{75}$ and another one from seven highincome countries. ${ }^{41}$ Fifteen studies included all cancer stages, ${ }^{16} 1721262829353638416474-77$ four studies restricted their analyses to stage III cancer, ${ }^{20} 2733$ five studies to stages I-III ${ }^{30-32} 3440$ and one study to stages II-III. ${ }^{37}$ Ten studies included all patients whatever their age at diagnosis, ${ }^{161727283234-363874}$ with the inclusion criterion for age varying widely in the remaining studies. All studies, with the exception of two, ${ }^{3841}$ analysed age at diagnosis using age categories but the number and boundaries of these varied across studies (table 2). Twelve studies presented relative survival (RS) estimates only, ${ }^{16}$ 28-30 $353638406474-76$ seven studies presented overall survival (OS) estimates only $^{2021262732373972}$ and two studies used net survival ${ }^{3877}$ (table 2). The remaining studies showed 30-day postoperative mortality rates, ${ }^{17}$ the cumulative incidence of death at 5 years, ${ }^{31}$ or mortality rates. ${ }^{33} 34$ 
2,139 references extracted on 30 Sept. 2019: EMBASE 430; MEDLINE 431; SCOPUS 644; Web of Science 634

908 references extracted on $18 \mathrm{Dec} .2020$ : EMBASE/MEDLINE 88; SCOPUS 275; Web of Science 545

$1,447(1241+206)$ references after duplicates removed

Exclusion $(n=263)$ :

77 No individual factor investigated

99 No stratification by age

4 No survival or mortality data

20 Not population-based study

16 Wrong age categories

23 Wrong cancer sites

2 Wrong designs

12 Wrong topics

3 Wrong populations

1 Not enough information to be included

5 No response from authors

1 More complete information in an included study

$307(116+191)$ retained on titles/abstracts

$13(2+11)$ additional references

2 known by SP

$59(35+24)$ full-texts included

Figure 1 Flow chart of studies' inclusion.

Of the 39 studies that examined lung cancer, 12 studies focused on non-small cell lung cancer (NSCLC), ${ }^{18 ~ 49-5559676872} 3$ studies on small-cell lung cancer (SCLC), ${ }^{195657}$ with the remaining studies investigating all lung cancer cases (table 3 ). Six studies evaluated age disparities in survival. ${ }^{46485053-55}$ Nine studies analysed data from the Netherlands, ${ }^{18} 194853-56596710$ studies from the USA ${ }^{4249525758656876}$ and the remaining studies presented data from Canada, ${ }^{66}{ }^{72}$ Denmark, ${ }^{60}$ Estonia, ${ }^{64} 78$ Sweden, ${ }^{70}$ Japan, ${ }^{63} 71$ Norway, ${ }^{73}$ Italy, ${ }^{61}$ Finland, ${ }^{74}$ Taiwan, ${ }^{43} 5169$ Korea, ${ }^{44}$ the Czech Republic, ${ }^{46}$ England $^{45} 77$ and Germany. ${ }^{47}$ Two studies used data from $>20$ Europeans countries. ${ }^{62} 75$ While most studies included all stages at diagnosis, some studies restricted their sample to specific stage (s): stage I cancer, ${ }^{50} 65-68$ stages I-IIIa, ${ }^{51}$ stages IIIb and IV $^{52}$ stage III $^{54}$ and stages I or II. ${ }^{55}$ Fifteen studies included patients of all ages at diagnosis, ${ }^{19} 4243464950535657596068707374$ other studies included patients from the age of 15 $(\mathrm{n}=11),^{18} 45475861-6475777818(\mathrm{n}=7),{ }^{48} 5165-67717220$ $(\mathrm{n}=3)^{446976}$ or $65 .^{525455}$ The studies used age categories that differed widely in terms of number and boundaries. Seventeen studies presented RS estimates only, $^{1819424446474953565861636473747678} 14$ studies OS estimates only, ${ }^{3} 4851525455596066-68707276 \quad 2$ studies net survival, ${ }^{45} \quad 77 \quad 1$ study presented cancer-specific survival (CSS) estimates, ${ }^{57} 3$ studies both OS and RS estimates $^{62} 7175$ and 1 study presented OS estimates and CSS. ${ }^{65}$ The one remaining study used mortality rates. ${ }^{69}$ 


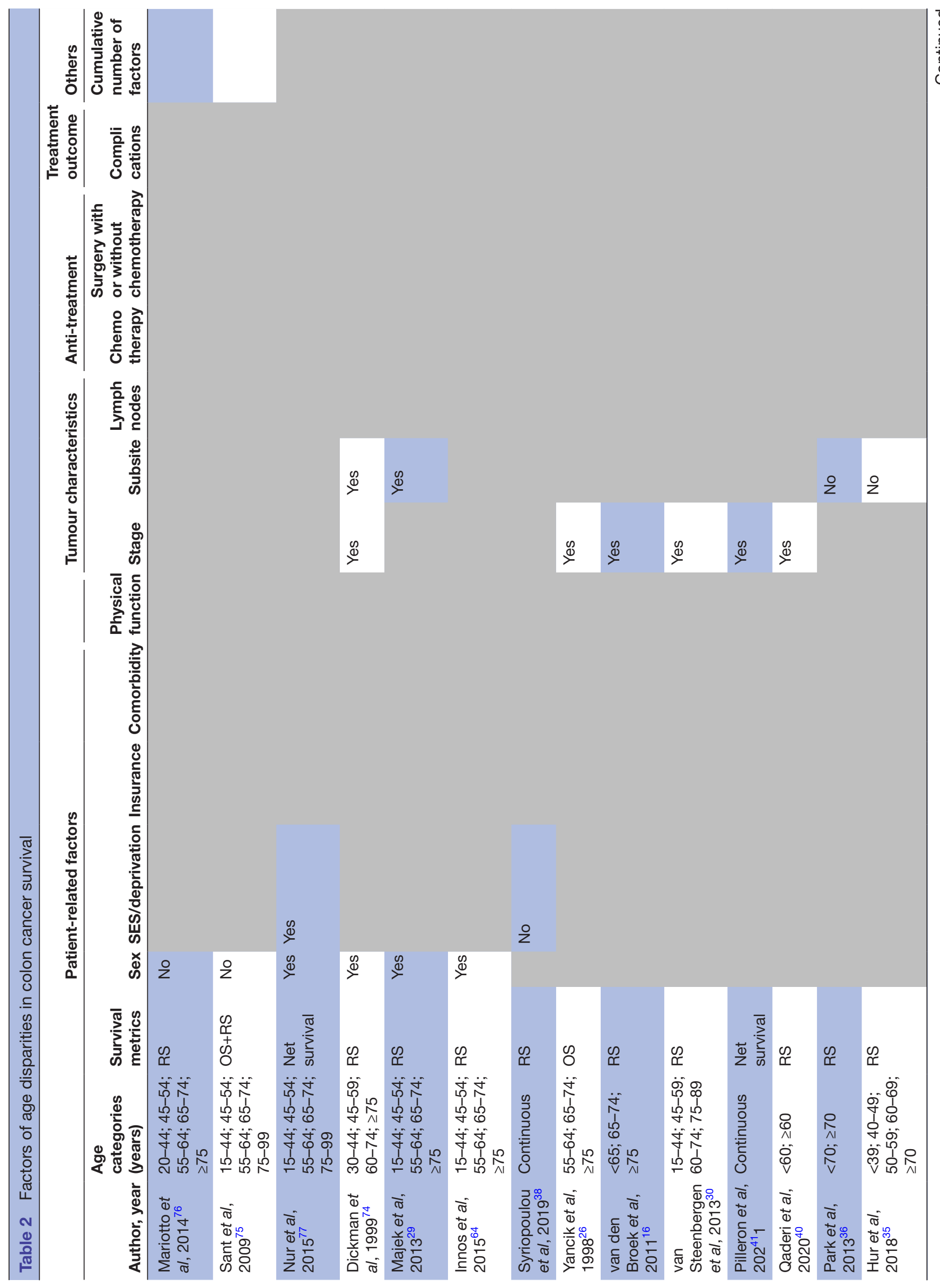




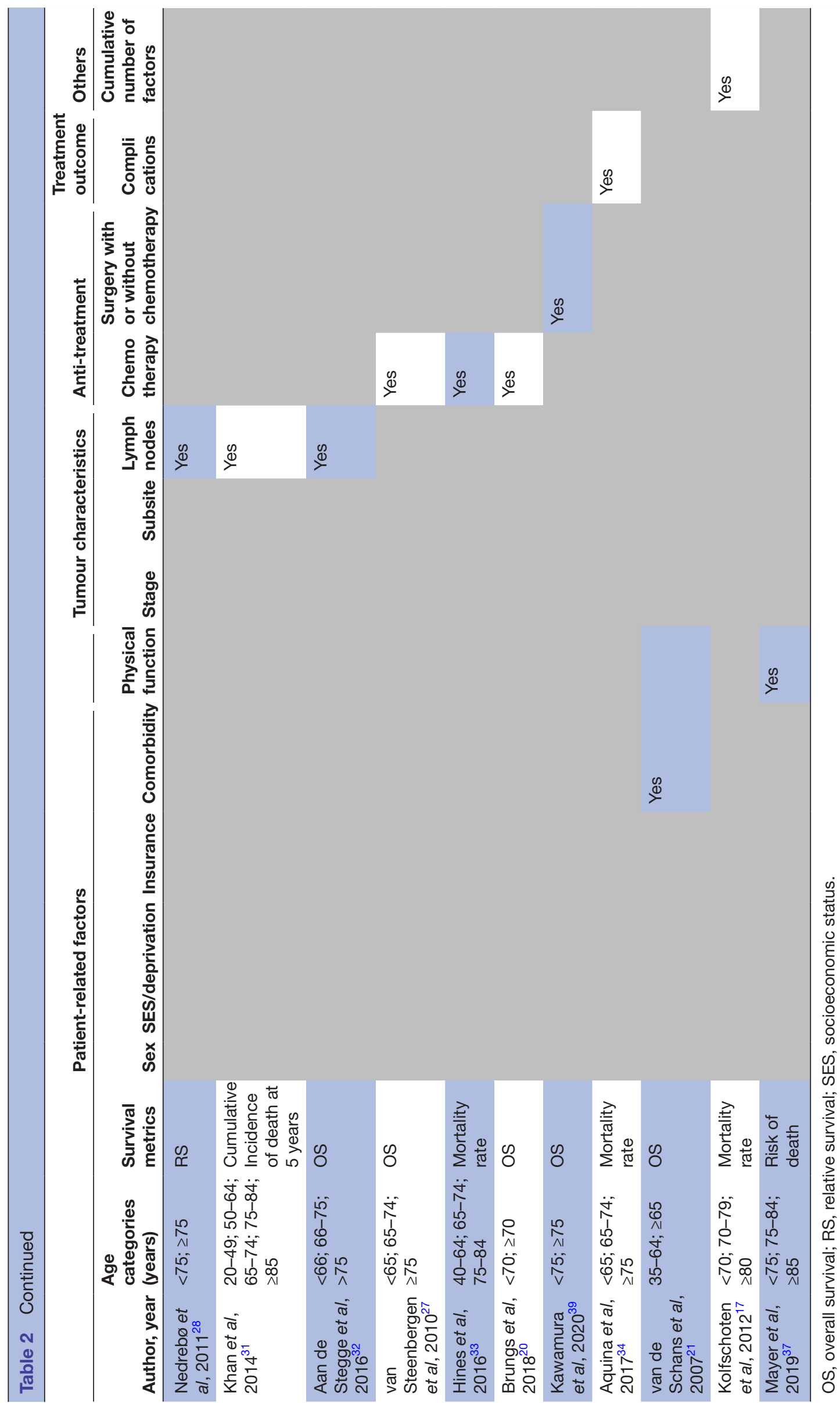




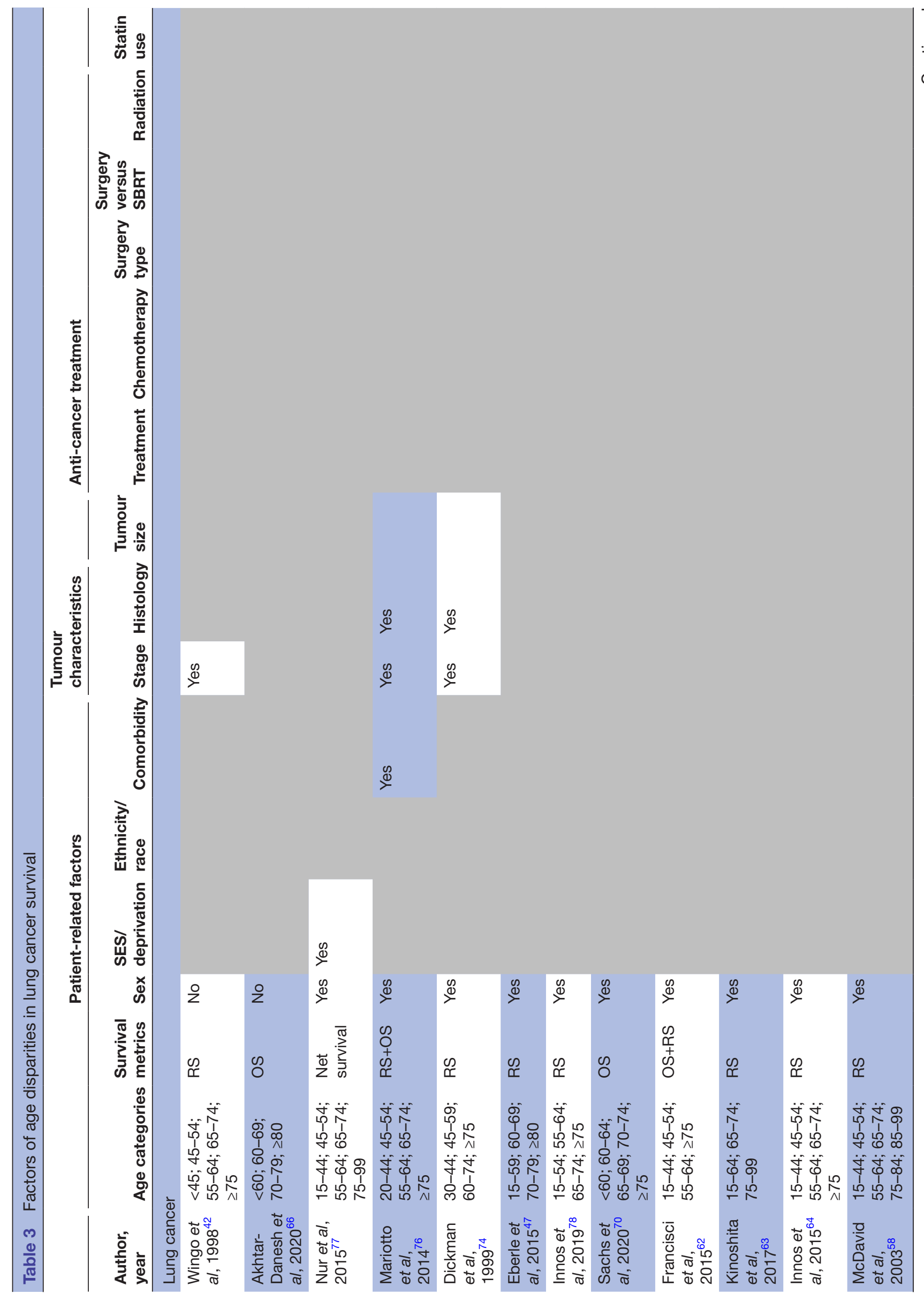




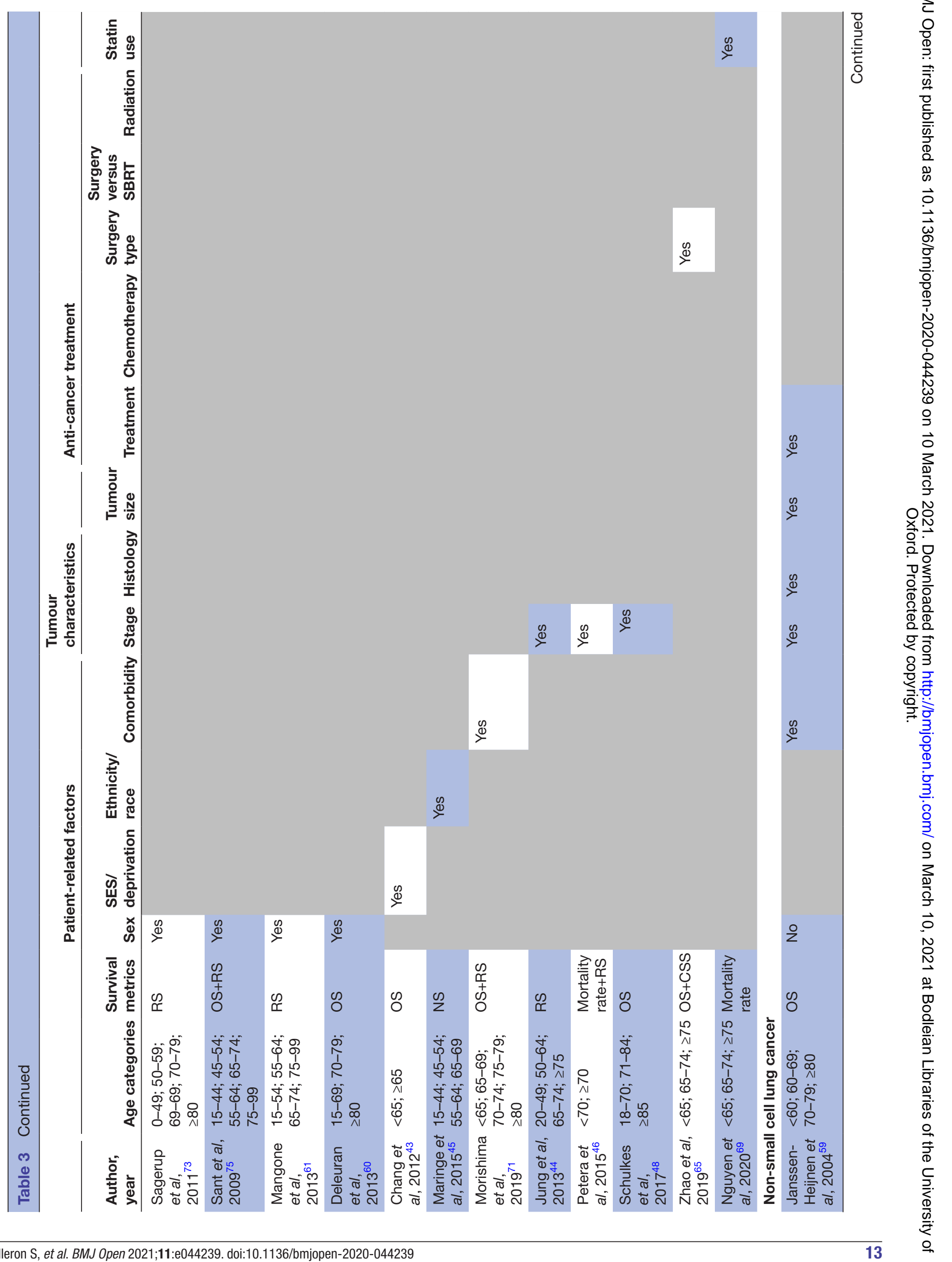




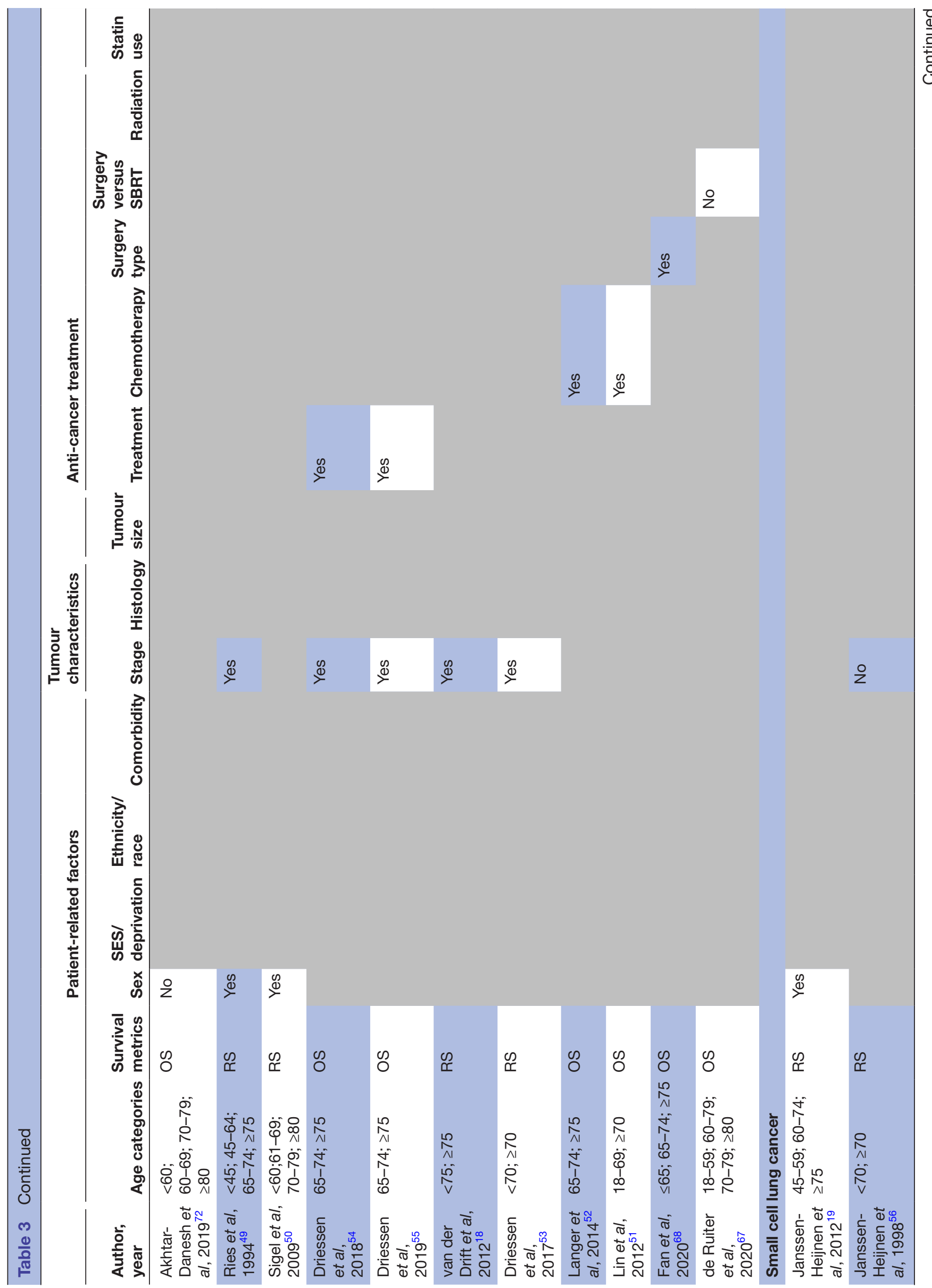




\section{Age patterns in colon and lung cancer surviva}

Patterns of age disparities in survival for colon and lung cancers based on patient-related and clinical factors are shown in tables 2 and 3, respectively. The detailed description of each included study is available in the online supplemental tables 5 and 6 .

Regarding colon cancer survival, higher age disparities were observed in women with regional or distant cancers, ${ }^{74}$ and those with left colon cancer, ${ }^{29}$ while the other studies did not find difference across sexes. ${ }^{647576}$ Another study suggests that age disparities across sexes differ based on socioeconomic deprivation level of domicile of patients, ${ }^{77}$ with higher age disparities in women observed after 1 year in deprived areas only. Age disparities in 5-year net survival were similar across sexes. One study found greater age disparities in deprived areas compared with affluent areas in England, ${ }^{77}$ while another study found no difference ${ }^{38}$ In another study, patients' physical function level did not influence age disparities in overall survival. ${ }^{37}$ Overall, age disparities were greater as cancer spread or when the cancer stage was unknown, ${ }^{16} 2630404174$ when lymph nodes were involved ${ }^{28}$ or when fewer than 12 nodes were examined. ${ }^{31} 32$ While some studies did not show different age patterns in survival based on subsite, ${ }^{35}$ others reported smaller age differences for patients with cancer of the distal colon compared with the proximal colon. $^{36}{ }^{74}$ Regarding treatment, the presence of bias precludes accurate interpretation, when studies presented survival data across treatment strategies. ${ }^{20} 273339$ One study reported postoperative mortality rates in patients who underwent an elective and non-elective resection. ${ }^{17}$ This study showed higher age disparities for men, for those with an American Society of Anesthesiologists score of $\geq 3$, for those with a Charlson comorbidity score $\geq 2$, for those with metastatic disease and for those with hemicolectomy. The study also concluded that complications and sepsis after surgery, ${ }^{34}$ as well as the presence of chronic obstructive pulmonary disease at the time of cancer diagnosis,${ }^{21}$ would also likely increase age disparities in colon cancer survival.

Regarding lung cancer survival, women had higher age disparities in survival in the majority of studies. 1947495058 60-63 74-78 However, in other studies, no differences were observed in age disparities between sexes ${ }^{596672} 73$ and another study found greater age disparities in men who underwent pulmonary resections. ${ }^{70} \mathrm{We}$ observed no clear pattern for the role of socioeconomic level on age disparities in data from one study, ${ }^{43}$ while another suggested smaller age disparities in deprived areas compared with affluent areas. ${ }^{77}$ Regarding the role of race/ethnicity, one study reported smaller age disparities in lung cancer survival among black patients compared with white patients in the USA. ${ }^{42}$ In comparison, South Asians showed greater age disparities than non-South Asians in the UK. ${ }^{45}$ One study suggested tumour size influenced age disparities, with disparities being greater in patients with larger tumours. ${ }^{59}$ Age disparities tended to decrease as the cancer spread ${ }^{424446495355-57597476}$ and 
were greater in patients with NSCLC than in those with SCLC. ${ }^{74} 76$ One study suggested that age disparities were smaller in patients with severe comorbidities than in those without comorbidity ${ }^{76}$ while another study showed greater age disparities with comorbidity, ${ }^{59}$ and another showed greater age disparities with comorbidities, but only in patients with localised NSCLC. ${ }^{59}$ Again, most studies presenting survival data by treatment group were at high risk of bias. ${ }^{1851545557656768}$ The only interpretable study showed that age disparities in overall survival did not differ based on the chemotherapy regimen. ${ }^{52} \mathrm{~A}$ study that focused on the relationship of statin use and survival in patients with lung cancer who received Epidermal growth factor receptor tyrosine kinase inhibitors (EGFR-TKI) therapy, showed greater age disparities in the statin group than in the non-statin group. ${ }^{69}$

\section{DISCUSSION}

This review is the first to bring together the literature on those factors which influence age disparities in cancer survival, using colon and lung cancer as exemplars. While age at diagnosis is an important prognostic factor in cancer survival, few studies, often of suboptimal quality, have specifically focused on the relationship between age and cancer survival, and only one has sought to identify patterns of age disparities in colon or lung cancer survival per se. However, our review showed that (1) the magnitude of disparities in survival between younger and older patients differed greatly and inconsistently based on patient and clinical characteristics; (2) the stage at diagnosis was the sole clinical characteristic that consistently influenced age disparities in survival, however opposite outcomes were seen for colon cancer and lung cancer; and (3) age disparities in lung cancer survival were typically greater in women than in men.

\section{Magnitude of age disparities in survival}

While in most studies older patients had poorer survival than middle-aged patients, this was not always the case. For instance, two studies reported no age disparity in cancer survival in patients with cancer of the right colon, ${ }^{2935}$ and other papers showed minimal age disparities in patients with advanced lung cancer, ${ }^{29}$ or small-cell lung carcinoma. ${ }^{74}$ On the other hand, age disparities were substantial in patients with distant colon cancer ${ }^{30} 74$ or those with localised lung cancer, ${ }^{42} 4649537476$ particularly for patients without comorbidities. ${ }^{76}$

\section{Clinical characteristics of age disparities in cancer survival}

The influence of stage at diagnosis on age disparities differed depending on the cancer. Age disparities in colon cancer survival tended to increase with increasing stage of disease, ${ }^{28}{ }^{30}$ while the opposite was observed for lung cancer. ${ }^{42} 4649537476$ Surgery is the main treatment strategy for patients with colon cancer diagnosed with localised and regional stage disease, while chemotherapy is recommended for metastatic disease. ${ }^{79}$ It has been shown that older patients are less likely to receive chemotherapy than younger patients, ${ }^{80-82}$ and less intensive therapies are usually recommended for unfit older patients. ${ }^{83}$ In lung cancer, older patients with early stage disease, especially those older than 75 , are less likely to undergo surgery compared with younger patients. ${ }^{84}$ The high lethality of the disease, especially at a more advanced stage, may explain the small difference in survival disparities observed between middle-aged and older patients with metastatic lung cancer.

Comorbidity, the prevalence of which drastically increases with age, is an important prognostic factor in patients with cancer, because it may complicate cancer management. ${ }^{85}$ However, our review identified four studies (one for colon cancer and three for lung cancer) reporting data for comorbidity, so few studies prevent us from making any firm conclusions regarding comorbidity and its impact on age disparities in cancer survival. One study suggested that the presence of chronic obstructive pulmonary disease at diagnosis may increase age disparities in survival seen in patients with colon cancer. ${ }^{21}$ Two studies showed greater age disparities in lung cancer survival in patients with comorbidity ${ }^{59}$ while another study suggested that patients without comorbidities showed greater age disparities in survival than those with severe comorbidities ${ }^{76}$ Comorbidity alone is not enough to assess vulnerabilities in older patients with cancer, and comprehensive geriatric assessments (CGA) may be useful in capturing a more nuanced view of health, fitness and physiological ageing. ${ }^{86}$ Although less valuable than information derived from CGA, it is now possible in many countries to link cancer survival data to comorbidity information through linkage with administrative hospitalisation data or pharmacy data, ${ }^{88}$ and thus further studies should be conducted, that describe the role of comorbidities on age disparities in survival, in patients with colon or lung cancer.

Unfortunately, we are unable to draw any conclusions regarding the role of treatment on age disparities in colon and lung cancer survival. Indeed, most studies presenting survival data by treatment group were at high risk of immortal time bias. ${ }^{27} 33545577$ Immortal time bias occurs when survival comparisons are made between groups of patients based on a factor (eg, treatment) that is defined after the start of follow-up (eg, cancer diagnosis date). Patients in the treated group survived long enough to be treated, while others in the untreated group may have died before having that chance. As a consequence, the treatment may be erroneously considered as effective because patients in the treated group have, on average, a better survival than those in the untreated group. In reality, the apparent better survival in the treated group may be the result of the selection of the fittest patients (ie, those who had the better chance to survive). For instance, this bias may be at play in the 2010 study of van Steenbergen et al and would explain the higher survival among the oldest age group in the 'no chemotherapy' group, ${ }^{27}$ or in the study of Sigel et al that reported higher 2-year RS in 
female patients older than 80 years compared with those younger than 60 years. ${ }^{50}$ With a few exceptions, ${ }^{34} 45527476$ the overall quality of studies included in this review was poor. Further high-quality studies are required if we are to better identify the role of treatment as a possible driver of age disparities in cancer survival.

\section{Patient-related factors of age disparities in cancer survival}

Only a few studies provided information about patient characteristics. The main patient characteristic examined in the colon cancer studies was sex, and the results were inconsistent. ${ }^{29}{ }^{64} 74-77$ Contradictory results were observed regarding the influence of socioeconomic deprivation level on age disparities in colon cancer survival, ${ }^{38} 77$ posing the need for specific research to investigate the potential role of deprivation. However, the included lung cancer studies suggested that the difference in 5-year survival between younger and older patients was wider in women than in men ${ }^{19} 424774$ but this was not necessarily the case for 1-year and 3-year survival. ${ }^{19}$ In the study by Dickman et al, women aged 45-59years had better 1-year RS than men of the same age; however, women aged 75 years or older had lower 1-year RS than their male counterparts. ${ }^{74}$ Even if some evidence suggests a positive effect of sex hormones on survival from NSCLC in women, ${ }^{89}$ the implication of sex hormones is still not clear. ${ }^{90}$ However, because of the observational nature of the studies included, survival bias may also be an explanation for the difference observed across sexes. In terms of race/ethnicity, age disparities in lung cancer survival seem to be influenced by race/ethnicity in the USA and the UK, but results are inconsistent, ${ }^{42}{ }^{45}$ probably because of differences between healthcare systems, or possible survival bias. Finally, the role of socioeconomic level in age disparities in lung cancer survival is not clear. ${ }^{43}$ While sex, ethnicity/race and socioeconomic level are known to influence cancer survival, ${ }^{91-93}$ their role in age disparities in cancer survival remain unclear and should be further explored.

Other characteristics may be important in explaining lower survival among older patients. When using observational data, data related to demographics and cancer are the easiest to study. With the exception of comorbidity, geriatric factors (ie, cognition, nutritional status, functional status) are not commonly studied, although these are important considerations in the management of cancer in older adults. ${ }^{94}$ Only one of the studies we reviewed investigated physical status and survival. ${ }^{37}$ No other factors influencing cancer management (such as performance status) were investigated in the included studies. Other factors, such as physical and financial access to cancer facilities, are likely to be more difficult to measure, and therefore were less likely to be included in this review.
The importance of choice of survival metric in future age disparity studies

Older adults have a higher risk of dying from causes other than cancer than younger adults. While of interest to patients and clinicians, ${ }^{95}$ OS measures are of limited value when studying disparities in survival between younger and older patients, mainly because they do not make a distinction between causes of death, and because of the higher risk of background mortality in older patients. Identifying the underlying cause of death may be challenging in older adults who may present with co-existing serious disease, making cancer-specific survival difficult to estimate. When studying the age disparities in survival, it is therefore crucial to take into account this difference in background mortality. Accordingly, relative survival (ie, the ratio of the observed survival among patients with cancer, over the (expected) survival among the general population obtained from national life tables) or net survival (ie, the probability of being alive after a defined period of time in the hypothetical world where one can die only from cancer) are suited to this purpose. However, life tables used to estimate the expected survival should be adequately stratified by likely important factors (eg, comorbidity, smoking status). ${ }^{96}$

\section{Limitations}

Our systematic review has limitations. We could not conduct any quantitative analysis (such as meta-analysis) because of the vast heterogeneity of the studies included, which prevented us from quantifying the relationship between increasing age and cancer survival. This is largely a reflection of the quality of the studies included in this review. We did, however, attempt to synthesise the available evidence into the key findings, as discussed above.

\section{Implications}

The rapidly increasing number of older patients with cancer ${ }^{14}$ has presented a dire need for a better understanding of the drivers of the disparities in colon and lung cancer survival between older and younger patients, ultimately enhancing the probability of patients surviving their cancer regardless of their age. While it is not realistic to believe that survival among older adults can equal that of middle-aged adults, there is more that can be done to minimise age disparities in colon and lung cancer survival-however the current quality of evidence prevents a full understanding of the key drivers of these disparities. As a first step for a better description of age disparities in survival, we encourage authors of future cancer survival studies to systematically present results stratified by age group, even if a study may not specifically focus on age. Geriatric factors that are important when managing cancer in older adults are not routinely captured by administrative data sets. Recent studies used hospitalisation data sets to define frailty or to identify patients with weight loss using general practices codes. ${ }^{97} 98$ Further studies of this kind are recommended for other factors (eg, functional status, cognition) and in other countries, 
and we encourage future cancer survival studies to consider presenting results stratified by age wherever possible. With the growth in the number of older patients with cancer, it is now time to improve the description of cancer survival prospects in this vital group.

\section{CONCLUSION}

In this systematic review, we have investigated age disparities in cancer survival using colon and lung cancer-two differing cancer contexts in terms of the likely impact of age on survival-as exemplars. The present review highlights both the lack of knowledge about age disparities in colon and lung cancer survival, and the absence of geriatric variables (eg, cognition, functional status, social support, nutritional status) investigated within current population-based research. With the growth of the use of administrative health data in several (high income) countries and an increased emphasis being placed on data quality, we can expect a more accurate description of age disparities in colon and lung cancer survival in the near future and a subsequent improved understanding of what drives them.

\section{Author affiliations}

${ }^{1}$ Department of Public Health, School of Medicine, University of Otago, Wellington, New Zealand

${ }^{2}$ Department of Surgery and Anaesthesia, Surgical Cancer Research Group, University of Otago, Wellington, New Zealand

${ }^{3}$ Department of Clinical Epidemiology, VieCuri Medical Centre, Venlo, The Netherlands

${ }^{4}$ Department of Epidemiology, Maastricht University Medical Centre+, GROW School for Oncology and Developmental Biology, Maastricht, The Netherlands

${ }^{5}$ Nuffield Department of Population Health, University of Oxford, Big Data Institute, Oxford, UK

${ }^{6}$ New Zealand Cancer Control Agency, Wellington, New Zealand

\section{Twitter Sophie Pilleron @Spilleron}

Contributors SP designed the study, wrote the protocol, screened all titles, abstracts and full-texts and drafted the manuscript. HG screened $10 \%$ of abstracts and full-texts, extracted data from included papers and critically reviewed the manuscript. VCS reviewed the protocol, screened $10 \%$ of titles and critically reviewed the manuscript. JKG critically reviewed the protocol and the manuscript. MJ-H helped with the interpretation and critically reviewed the manuscript. RC supervised the study, helped with the interpretation and critically reviewed the manuscript. EJAM helped with the interpretation and critically reviewed the manuscript. DS helped with the interpretation and critically reviewed the manuscript.

Funding SP has received funding from the European Union's Horizon 2020 research and innovation programme under the Marie Skłodowska-Curie grant agreement № 842817.

Competing interests None declared.

Patient consent for publication Not required.

Provenance and peer review Not commissioned; externally peer reviewed.

Data availability statement Data available within the article and its supplementary materials.

Supplemental material This content has been supplied by the author(s). It has not been vetted by BMJ Publishing Group Limited (BMJ) and may not have been peer-reviewed. Any opinions or recommendations discussed are solely those of the author(s) and are not endorsed by BMJ. BMJ disclaims all liability and responsibility arising from any reliance placed on the content. Where the content includes any translated material, BMJ does not warrant the accuracy and reliability of the translations (including but not limited to local regulations, clinical guidelines, terminology, drug names and drug dosages), and is not responsible for any error and/or omissions arising from translation and adaptation or otherwise.

Open access This is an open access article distributed in accordance with the Creative Commons Attribution Non Commercial (CC BY-NC 4.0) license, which permits others to distribute, remix, adapt, build upon this work non-commercially, and license their derivative works on different terms, provided the original work is properly cited, appropriate credit is given, any changes made indicated, and the use is non-commercial. See: http://creativecommons.org/licenses/by-nc/4.0/.

\section{ORCID iDs}

Sophie Pilleron http://orcid.org/0000-0001-7146-4740

Jason K Gurney http://orcid.org/0000-0002-7615-0748

Ruth Cunningham http://orcid.org/0000-0003-0090-3579

\section{REFERENCES}

1 Bassily MN, Wilson R, Pompei F, et al. Cancer survival as a function of age at diagnosis: a study of the surveillance, epidemiology and end results database. Cancer Epidemiol 2010;34:667-81.

2 Quaglia A, Tavilla A, Shack L, et al. The cancer survival gap between elderly and middle-aged patients in Europe is widening. Eur $\mathrm{J}$ Cancer 2009;45:1006-16.

3 Brenner $\mathrm{H}$, Arndt V. Recent increase in cancer survival according to age: higher survival in all age groups, but widening age gradient. Cancer Causes Control 2004;15:903-10.

4 De Angelis R, Sant M, Coleman MP, et al. Cancer survival in Europe 1999-2007 by country and age: results of EUROCARE--5-a population-based study. Lancet Oncol 2014;15:23-34.

5 Colonna M, Bossard N, Remontet L, et al. Changes in the risk of death from cancer up to five years after diagnosis in elderly patients: a study of five common cancers. Int J Cancer 2010;127:924-31.

6 Zeng C, Wen W, Morgans AK, et al. Disparities by race, age, and sex in the improvement of survival for major cancers: results from the National cancer Institute surveillance, epidemiology, and end results (SEER) program in the United States, 1990 to 2010. JAMA Oncol 2015;1:88-96.

7 Arnold M, Rutherford MJ, Bardot A, et al. Progress in cancer survival, mortality, and incidence in seven high-income countries 1995-2014 (ICBP SURVMARK-2): a population-based study. Lancet Oncol 2019;20:1493-505.

8 Balducci L. Studying cancer treatment in the elderly patient population. Cancer Control 2014;21:215-20.

9 Hutchins LF, Unger JM, Crowley JJ, et al. Underrepresentation of patients 65 years of age or older in cancer-treatment trials. $N$ Engl $J$ Med 1999;341:2061-7.

10 Lewis JH, Kilgore ML, Goldman DP, et al. Participation of patients 65 years of age or older in cancer clinical trials. JCO 2003;21:1383-9.

11 Shahrokni A, Sun C-L, Tew WP, et al. The association between social support and chemotherapy-related toxicity in older patients with cancer. J Geriatr Oncol 2020;11:274-9.

12 Williams GR, Pisu M, Rocque GB, et al. Unmet social support needs among older adults with cancer. Cancer 2019;125:473-81.

13 Galvin A, Delva F, Helmer C, et al. Sociodemographic, socioeconomic, and clinical determinants of survival in patients with cancer: a systematic review of the literature focused on the elderly. $J$ Geriatr Oncol 2018;9:6-14.

14 Pilleron S, Sarfati D, Janssen-Heijnen M, et al. Global cancer incidence in older adults, 2012 and 2035: a population-based study. Int J Cancer 2019;144:49-58.

15 Janssen-Heijnen MLG, Gondos A, Bray F, et al. Clinical relevance of conditional survival of cancer patients in Europe: age-specific analyses of 13 cancers. J Clin Oncol 2010;28:2520-8.

16 van den Broek CBM, Dekker JWT, Bastiaannet E, et al. The survival gap between middle-aged and elderly colon cancer patients. time trends in treatment and survival. Eur J of Oncol 2011;37:904-12.

17 Kolfschoten NE, Wouters MWJM, Gooiker GA, et al. Nonelective colon cancer resections in elderly patients: results from the Dutch surgical colorectal audit. Dig Surg 2012;29:412-9.

18 van der Drift MA, Karim-Kos HE, Siesling S, et al. Progress in standard of care therapy and modest survival benefits in the treatment of non-small cell lung cancer patients in the Netherlands in the last 20 years. J Thorac Oncol 2012;7:291-8.

19 Janssen-Heijnen MLG, Karim-Kos HE, van der Drift MA, et al. Modest improvements of survival for patients with small cell lung cancer aged 45 to 59 years only, diagnosed in the Netherlands, 1989 to 2008. J Thorac Oncol 2012;7:227-32.

20 Brungs D, Aghmesheh M, de Souza P, et al. Safety and efficacy of oxaliplatin doublet adjuvant chemotherapy in elderly patients with stage III colon cancer. Clin Colorectal Cancer 2018;17:e549-55. 
21 van de Schans SAM, Janssen-Heijnen MLG, Biesma B, et al. COPD in cancer patients: higher prevalence in the elderly, a different treatment strategy in case of primary tumours above the diaphragm, and a worse overall survival in the elderly patient. Eur $J$ Cancer 2007;43:2194-202.

22 Hayden JA, van der Windt DA, Cartwright JL, et al. Assessing bias in studies of prognostic factors. Ann Intern Med 2013:158:280-6.

23 Altman DG, De Stavola BL, Love SB, et al. Review of survival analyses published in cancer journals. Br J Cancer 1995;72:511-8.

24 Ouzzani M, Hammady H, Fedorowicz Z, et al. Rayyan-a web and mobile APP for systematic reviews. Syst Rev 2016;5:210.

25 Moher D, Liberati A, Tetzlaff J, et al. Preferred reporting items for systematic reviews and meta-analyses: the PRISMA statement. PLoS Med 2009;6:e1000097.

26 Yancik R, Wesley MN, Ries LA, et al. Comorbidity and age as predictors of risk for early mortality of male and female colon carcinoma patients: a population-based study. Cancer 1998;82:2123-34.

27 van Steenbergen LN, Elferink MAG, Krijnen P, et al. Improved survival of colon cancer due to improved treatment and detection: a nationwide population-based study in the Netherlands 1989-2006. Ann Oncol 2010;21:2206-12.

28 Nedrebø BS, Søreide K, Eriksen MT, et al. Survival effect of implementing national treatment strategies for curatively resected colonic and rectal cancer. Br J Surg 2011;98:716-23.

29 Majek O, Gondos A, Jansen L, et al. Sex differences in colorectal cancer survival: population-based analysis of 164,996 colorectal cancer patients in Germany. PLoS One 2013;8:e68077.

30 van Steenbergen LN, Steur M, Lemmens VEPP, et al. Minimal excess mortality for long-term colon cancer survivors in the Netherlands 1989-2008. Eur J Cancer 2013:49:585-92.

31 Khan H, Olszewski AJ, Somasundar P. Lymph node involvement in colon cancer patients decreases with age; a population based analysis. Eur J Surg Oncol 2014;40:1474-80.

32 Aan de Stegge WB, van Leeuwen BL, Elferink MAG, et al. The evaluation of more lymph nodes in colon cancer is associated with improved survival in patients of all ages. PLoS One 2016;11:e0155608

33 Hines RB, Bimali M, Johnson AM, et al. Prevalence and survival benefit of adjuvant chemotherapy in stage III colon cancer patients: comparison of overall and age-stratified results by multivariable modeling and propensity score methodology in a population-based cohort. Cancer Epidemiol 2016;44:77-83.

34 Aquina CT, Mohile SG, Tejani MA, et al. The impact of age on complications, survival, and cause of death following colon cancer surgery. Br J Cancer 2017;116:389-97.

35 Hur H, Oh C-M, Won Y-J, et al. Characteristics and survival of Korean patients with colorectal cancer based on data from the Korea central cancer registry data. Ann Coloproctol 2018;34:212-21.

36 Park H-C, Shin A, Kim B-W, et al. Data on the characteristics and the survival of Korean patients with colorectal cancer from the Korea central cancer registry. Ann Coloproctol 2013;29:144-9.

37 Mayer SE, Tan H-J, Peacock Hinton S, et al. Comparison of Medicare Claims-based proxy measures of poor function and associations with treatment receipt and mortality in older colon cancer patients. Med Care 2019;57:286-94

38 Syriopoulou E, Morris E, Finan PJ, et al. Understanding the impact of socioeconomic differences in colorectal cancer survival: potential gain in life-years. Br J Cancer 2019;120:1052-8.

39 Kawamura H, Morishima T, Sato A, et al. Effect of adjuvant chemotherapy on survival benefit in stage III colon cancer patients stratified by age: a Japanese real-world cohort study. BMC Cancer 2020;20:19.

40 Qaderi SM, Dickman PW, de Wilt JHW, et al. Conditional surviva and cure of patients with colon or rectal cancer: a population-based study. J Natl Compr Canc Netw 2020;18:1230-7.

41 Pilleron S, Charvat H, Araghi M, et al. Age disparities in stagespecific colon cancer survival across seven countries: an international cancer benchmarking partnership SURVMARK-2 population-based study. Int J Cancer 2021;148:1575-1585.

42 Wingo PA, Ries LAG, Parker SL. Long-term cancer patient survival in the United States. Cancer Epidemiology Biomarkers \& Prevention 1998;7:271-82

43 Chang C-M, Su Y-C, Lai N-S, et al. The combined effect of individua and neighborhood socioeconomic status on cancer survival rates. PLoS One 2012;7:e44325.

44 Jung K-W, Won Y-J, Kong H-J, et al. Survival of Korean adult cancer patients by stage at diagnosis, 2006-2010: National cancer registry study. Cancer Res Treat 2013;45:162-71.

45 Maringe C, Li R, Mangtani P, et al. Cancer survival differences between South Asians and non-South Asians of England in 1986-
2004, accounting for age at diagnosis and deprivation. Br J Cancer 2015;113:173-81.

46 Petera J, Dušek L, Sirák I, et al. Cancer in the elderly in the Czech Republic. Eur J Cancer Care 2015;24:163-78.

47 Eberle A, Jansen L, Castro F, et al. Lung cancer survival in Germany: a population-based analysis of 132,612 lung cancer patients. Lung Cancer 2015:90:528-33.

48 Schulkes KJG, Pouw CAM, Driessen EJM, et al. Lung cancer in the oldest old: a nation-wide study in the Netherlands. Lung 2017;195:627-34.

49 Ries LA. Influence of extent of disease, histology, and demographic factors on lung cancer survival in the SEER population-based data. Semin Surg Oncol 1994;10:21-30.

50 Sigel K, Bonomi M, Packer S, et al. Effect of age on survival of clinical stage I non-small-cell lung cancer. Ann Surg Oncol 2009;16:1912-7

51 Lin Z-Z, Shau W-Y, Shao Y-Y, et al. Survival following surgery with or without adjuvant chemotherapy for stage I-IIIA non-small cell lung cancer: an East Asian population-based study. Oncologist 2012;17:1294-302

52 Langer C, Ravelo A, Hazard SJ, et al. Comparison of survival and hospitalization rates between Medicare patients with advanced NSCLC treated with bevacizumab-carboplatin-paclitaxel and carboplatin-paclitaxel: a retrospective cohort study. Lung Cancer 2014;86:350-7.

53 Driessen EJ, Aarts MJ, Bootsma GP, et al. Trends in treatment and relative survival among non-small cell lung cancer patients in the Netherlands (1990-2014): disparities between younger and older patients. Lung Cancer 2017;108:198-204.

54 Driessen EJM, Schulkes KJG, Dingemans A-MC, et al. Patterns of treatment and survival among older patients with stage III non-small cell lung cancer. Lung Cancer 2018;116:55-61.

55 Driessen E, Detillon D, Bootsma G, et al. Population-based patterns of treatment and survival for patients with stage I and II non-smal cell lung cancer aged $65-74$ years and 75 years or older. J Geriatr Oncol 2019;10:547-54.

56 Janssen-Heijnen ML, Schipper RM, Klinkhamer PJ, et al. Improvement and plateau in survival of small-cell lung cancer since 1975: a population-based study. Ann Oncol 1998:9:543-7.

57 Wang $\mathrm{H}$, Zhang J, Shi F, et al. Better cancer specific survival in young small cell lung cancer patients especially with AJCC stage III. Oncotarget 2017;8:34923-34.

58 McDavid K, Tucker TC, Sloggett A, et al. Cancer survival in Kentucky and health insurance coverage. Arch Intern Med 2003;163:2135-44.

59 Janssen-Heijnen MLG, Smulders S, Lemmens VEPP, et al. Effect of comorbidity on the treatment and prognosis of elderly patients with non-small cell lung cancer. Thorax 2004;59:602-7.

60 Deleuran T, Thomsen RW, Nørgaard M, et al. Comorbidity and survival of Danish lung cancer patients from 2000-2011: a population-based cohort study. Clin Epidemiol 2013;5:31-8

61 Mangone L, Minicozzi P, Vicentini M, et al. Key factors influencing lung cancer survival in northern Italy. Cancer Epidemiol 2013;37:226-32

62 Francisci S, Minicozzi P, Pierannunzio D, et al. Survival patterns in lung and pleural cancer in Europe 1999-2007: results from the EUROCARE-5 study. Eur J Cancer 2015;51:2242-53.

63 Kinoshita FL, Ito Y, Morishima T, et al. Sex differences in lung cancer survival: long-term trends using population-based cancer registry data in Osaka, Japan. Jpn J Clin Oncol 2017;47:863-9.

64 Innos K, Padrik P, Valvere V, et al. Sex differences in cancer survival in Estonia: a population-based study. BMC Cancer 2015;15:72.

65 Zhao M, Lu T, Huang Y, et al. Survival and long-term cause-specific mortality associated with stage la lung adenocarcinoma after wedge resection vs. Segmentectomy: a population-based propensity score matching and competing risk analysis. Front Oncol 2019;9:593.

66 Akhtar-Danesh G-G, Finley C, Seow HY, et al. Change in treatment modality and trends in survival among stage I non-small cell lung cancer patients: a population-based study. J Thorac Dis 2020;12:4670-9.

67 de Ruiter JC, Heineman DJ, Daniels JM, et al. The role of surgery for stage I non-small cell lung cancer in octogenarians in the era of stereotactic body radiotherapy in the Netherlands. Lung Cancer 2020;144:64-70.

68 Fan X, Liang Y, Bai Y, et al. Conditional survival rate estimates of lobectomy, segmentectomy and wedge resection for stage IA1 non-small cell lung cancer: a population-based study. Oncol Lett 2020;20:1607-18.

69 Nguyen P-A, Chang C-C, Galvin CJ, et al. Statins use and its impact in EGFR-TKIs resistance to prolong the survival of lung cancer patients: a cancer registry cohort study in Taiwan. Cancer Sci 2020;111:2965-73. 
70 Sachs E, Sartipy U, Jackson V. Sex and survival after surgery for lung cancer: a Swedish nationwide cohort. Chest 2020. doi:10.1016/j. chest.2020.11.010. [Epub ahead of print: 17 Nov 2020].

71 Morishima T, Matsumoto Y, Koeda N, et al. Impact of comorbidities on survival in gastric, colorectal, and lung cancer patients. $J$ Epidemiol 2019;29:110-5.

72 Akhtar-Danesh N, Akhtar-Danseh G-G, Seow HY, et al. Trends in survival based on treatment modality in non-small cell lung cancer patients: a population-based study. Cancer Invest 2019;37:355-66.

73 Sagerup CMT, Småstuen M, Johannesen TB, et al. Sex-Specific trends in lung cancer incidence and survival: a population study of 40,118 cases. Thorax 2011;66:301-7.

74 Dickman PW, Hakulinen T, Luostarinen T, et al. Survival of cancer patients in Finland 1955-1994. Acta Oncol 1999;38 Suppl 12:1-103.

75 Sant M, Allemani C, Santaquilani M, et al. Eurocare-4. survival of cancer patients diagnosed in 1995-1999. results and commentary. Eur J Cancer 2009;45:931-91.

76 Mariotto AB, Noone A-M, Howlader N, et al. Cancer survival: an overview of measures, uses, and interpretation. J Natl Cancer Inst Monogr 2014;2014:145-86.

77 Nur U, Lyratzopoulos G, Rachet B, et al. The impact of age at diagnosis on socioeconomic inequalities in adult cancer survival in England. Cancer Epidemiol 2015;39:641-9.

78 Innos K, Oselin K, Laisaar T, et al. Patterns of survival and surgical treatment in lung cancer patients in Estonia by histologic type and stage, 1996-2016. Acta Oncol 2019;58:1549-56.

79 Schmoll HJ, Van Cutsem E, Stein A, et al. ESMO consensus guidelines for management of patients with colon and rectal cancer. A personalized approach to clinical decision making. Ann Oncol 2012;23:2479-516.

80 Merchant SJ, Nanji S, Brennan K, et al. Management of stage III colon cancer in the elderly: practice patterns and outcomes in the general population. Cancer 2017;123:2840-9.

81 Raycraft T, Cheung WY, Yin Y, et al. Causes of mortality in older patients with stage 3 colon cancer. J Geriatr Oncol 2019;10:138-42.

82 Sarasqueta C, Perales A, Escobar A, et al. Impact of age on the use of adjuvant treatments in patients undergoing surgery for colorectal cancer: patients with stage III colon or stage II/III rectal cancer. BMC Cancer 2019;19:735

83 Van Cutsem E, Cervantes A, Adam R, et al. ESMO consensus guidelines for the management of patients with metastatic colorectal cancer. Ann Oncol 2016;27:1386-422.

84 Belot A, Fowler H, Njagi EN, et al. Association between age, deprivation and specific comorbid conditions and the receipt of major surgery in patients with non-small cell lung cancer in England: a population-based study. Thorax 2019;74:51-9.
85 Sarfati D, Koczwara B, Jackson C. The impact of comorbidity on cancer and its treatment. CA Cancer J Clin 2016;66:337-50.

86 Mohile SG, Dale W, Somerfield MR, et al. Practical assessment and management of vulnerabilities in older patients receiving chemotherapy: ASCO guideline for geriatric oncology. JCO 2018;36:2326-47.

87 Sarfati D, Hill S, Purdie G, et al. How well does routine hospitalisation data capture information on comorbidity in New Zealand? N Z Med J 2010;123:50-61.

88 Sarfati D, Gurney J, Stanley J, et al. Development of a pharmacybased comorbidity index for patients with cancer. Med Care 2014;52:586-93.

89 Katcoff H, Wenzlaff A, Schwartz A. Survival in women with NSCLC. J Thorac Oncol 2014;9:355-61.

90 Townsend EA, Miller VM, Prakash YS. Sex differences and sex steroids in lung health and disease. Endocr Rev 2012;33:1-47.

91 Hill S, Sarfati D, Blakely T, et al. Survival disparities in Indigenous and non-Indigenous new Zealanders with colon cancer: the role of patient comorbidity, treatment and health service factors. $J$ Epidemiol Community Health 2010;64:117-23.

92 Ellis L, Coleman MP, Rachet B. How many deaths would be avoidable if socioeconomic inequalities in cancer survival in England were eliminated? a national population-based study, 1996-2006. Eur J Cancer 2012;48:270-8.

93 Radkiewicz C, Dickman PW, Johansson ALV, et al. Sex and survival in non-small cell lung cancer: a nationwide cohort study. PLoS One 2019;14:e0219206.

94 Wildiers $\mathrm{H}$, Heeren $\mathrm{P}$, Puts $\mathrm{M}$, et al. International Society of geriatric oncology consensus on geriatric assessment in older patients with cancer. J Clin Oncol 2014;32:2595-603.

95 Belot A, Ndiaye A, Luque-Fernandez M-A, et al. Summarizing and communicating on survival data according to the audience: a tutorial on different measures illustrated with population-based cancer registry data. Clin Epidemiol 2019;11:53-65.

96 Sarfati D, Blakely T, Pearce N. Measuring cancer survival in populations: relative survival vs cancer-specific survival. Int $J$ Epidemiol 2010;39:598-610.

97 Gilbert T, Neuburger J, Kraindler J, et al. Development and validation of a hospital frailty risk score focusing on older people in acute care settings using electronic Hospital records: an observational study. Lancet 2018;391:1775-82.

98 Nicholson BD, Aveyard P, Hobbs FDR, et al. Weight loss as a predictor of cancer and serious disease in primary care: an ISACapproved CPRD protocol for a retrospective cohort study using routinely collected primary care data from the UK. Diagn Progn Res 2018;2:1-26. 